\title{
INSIGHTS FROM ONLINE CONSUMER REVIEWS [OCR] FOR ‘COVID19 GENERATION PRODUCTS’
}

\author{
Sudhakar@Vijayakumar, \\ Research Scholar, Department of Management Studies, Pondicherry University, Pondicherry 605014 \\ Email: sudhakar.explore@gmail.com
}

\section{S. Riasudeen,}

Associate Professor, Department of Management Studies, Pondicherry University, Pondicherry 605014 Email: riasudeen@yahoo.co.in

\section{R. Venkatesakumar,}

Professor, Department of Management Studies, Pondicherry University, Pondicherry 605014

Email: venkatesh1316@gmail.com

and

\section{S. Madhavan,}

Professor, Department of Management Studies, Manonmaniam Sundaranar University, Tirunelveli 627012 Email: madhavan@msuniv.ac.in

ABSTRACT
Purpose: $\quad$ The pandemic virus spread COVID19 drives the use of sanitizers and masks. To broaden the online review characteristics like review length, star rating and sentiment scores for the masks and sanitizers, the product reviews are analysed through text analytics procedures on the time stamp from March 2020 to June 2020.

Design

/methodology

/approach:

Findings:

Originality:
With a specific set of research variables and hypotheses, the study fits into a descriptive research design.From the online product reviews of masks and sanitizers, random reviews are collected.In addition to the star rating in the consumer reviews, we have computed review length and sentiment scores. The review characteristics like review length, star rating and the sentiment scores are analysed across the time intervals [Before March 2020, March/April 2020, May 2020 and June 2020].

From the masks and sanitizer data, we have found that the review lengths are varying significantly for masks on the time stamp. The star rating assigned and sentiment scores of the reviews have seen a decreasing trend in the timeline for the masks and sanitizer.

Research work addressing the product categories like masks and sanitizersis a new study context. The star ratings and the sentiment scores from the online reviews of the consumers for the masks and sanitizers are unique contributions from this research work.

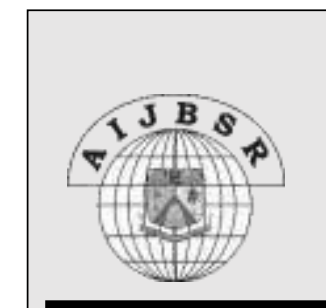

Vol. 11 Issue 1 Jan. 2021 PP DOI:

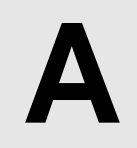

$\mathbf{J}$

B
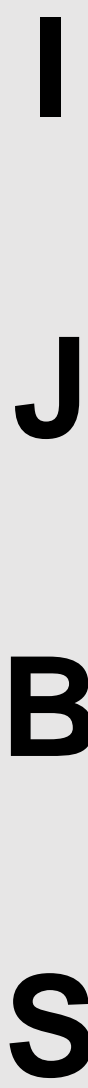

$\mathbf{R}$ 